\title{
Heridas por mordida animal en región maxilofacial. Revisión de literatura y presentación de casos
}

\author{
Animal bite injuries in maxillofacial region. \\ Literature review and cases presentation
}

Juan J Trujillo-Fandiño,* Víctor M González-Olmedo

\section{RESUMEN}

Las heridas por mordida en la región maxilofacial son relativamente comunes, se consideran de tratamiento complejo, contaminadas con una flora bacteriana única y en ocasiones con resultados estéticos devastadores. Las heridas pueden ser ocasionadas por animales domésticos, salvajes y por humanos. El clínico debe tener una compresión multidisciplinaria sobre el manejo de las mismas, dentro de las que se incluye el manejo médico, quirúrgico, viral, bacteriológico y la secuencia propia del tratamiento. Se presenta la revisión literaria así como casos clínicos para el manejo integral de este tipo de trauma.

Palabras clave: Heridas por mordida, cierre primario, infección de herida.

\section{ABSTRACT}

Bite wounds in the maxillofacial region are relatively common, they have been considered of complex treatment, contaminated with a unique polymicrobial inoculum and in occasions with devastating cosmetic results. Domestic and wild animal and humans may cause the wounds. The clinician should have an understanding of the surgical therapy, medical therapy, virology, bacteriology and the proper sequence of treatment. We present the literature review and clinical cases for the integral management of this type of trauma.

Keywords: Bite wound, primary closure, wound infection.

\section{* Subjefe de Servicio de Cirugía Maxilofacial. \\ ‡ Residente de $4^{\circ}$ año de Cirugía Maxilofacial. \\ Hospital Juárez de México. Ciudad de México, México. \\ Correspondencia: \\ Dr. Víctor Manuel González Olmedo}

Av. Instituto Politécnico Nacional Núm. 5160, Col. Magdalena de las Salinas, consultorio 27, primer piso, consulta externa, 07760 ,

Gustavo A. Madero, Ciudad de México, México.Tel: 55 5747-7560

E-mail: victor_go7@hotmail.com

Citar como: Trujillo-Fandiño JJ, González-Olmedo VM. Heridas por mordida animal en región maxilofacial. Revisión de literatura y presentación de casos. Rev Mex Cir Bucal Maxilofac. 2020; 16 (2 y 3): 103-109. https://dx.doi.org/10.35366/97708 


\section{INTRODUCCIÓN}

Las heridas faciales por mordida de animales son complejas y ocurren con relativa frecuencia en la región maxilofacial..$^{1,2}$ La morbilidad relacionada con este tipo de heridas así como las implicaciones estéticas demandan un tratamiento cuidadoso y la aplicación de estrategias bien documentadas para su manejo. ${ }^{1}$ Se estima que alrededor de 44,000 personas son afectadas al año en los Estados Unidos. ${ }^{2,3}$

Las heridas por mordida de perro no son traumatismos recientes, Lowry en 1936 reportó 122 casos, de los cuales $8 \%$ eran heridas en la región facial. Boland en 1941 reportó 60 casos, de los cuales 40\% involucraban la cabeza y cuello., ${ }^{1,2}$

El perro doméstico es sin duda el agresor más frecuente con 80 a $90 \%$, se le atribuye principalmente a los caninos propios así como a los de los vecinos de una comunidad. ${ }^{2}$ El gato doméstico se cree que ocasiona de 5 a $15 \%$ de los casos. ${ }^{4,5}$ Si bien es cierto que ocurren con menor frecuencia, los animales salvajes son parte de los casos reportados, esto es relativo a la fauna de la comunidad o al área étnica del habitante. ${ }^{5,6}$ Dentro de los animales salvajes que se ven implicados en estos incidentes, se incluyen los mapaches, zorrillos y murciélagos que reportan $6 \%$. Los animales de granja constituyen 3\% de las mordidas, dentro de los que se incluyen los caballos, vacas y ovejas.

La incidencia es mayor en el sexo masculino que el femenino. La mayoría de las víctimas tienen una edad entre 5 y 15 años, siendo la cabeza y el cuello el área más afectada por la fisionomía anatómica y desarrollo. ${ }^{5,7}$

Si bien es cierto que el canino es por mucho el mayor actor de estos incidentes, es importante conocer las razas que con mayor frecuencia lo hacen. Dentro de las razas existen algunas con mayor índice de casos, esto por la naturaleza individual de cada raza, ya que tienden a ser más agresivos y territoriales que otros, lo que los hace más propensos a estos ataques. ${ }^{4,5}$ La raza que más relacionada con este tipo de actos es el pitbull (25\%), labrador (12\%), chow chow (10\%), pastor alemán (10\%), rottweiler $(10 \%)$ y dóberman (5\%). ${ }^{4,5,7}$ Las heridas propiciadas por este tipo de animales pueden ser letales debido a la alta agresividad con la que atacan y el peso que llegan a tener, lo cual hace difícil para el atacado poder defenderse. La hemorragia exanguinante es la causa principal de muerte así como el compromiso de la vía aérea y trauma craneofacial, principalmente en los ataques de animales grandes. ${ }^{2,5}$
La fuerza emitida por la mordida de un animal puede alcanzar hasta $800 \mathrm{~kg}$ de presión,,5 lo que puede ocasionar la necrosis del tejido afectado por trituración, desgarro, avulsión o una combinación de los anteriores.

Conocer el patrón de las mordidas ocasionadas puede brindar al clínico información importante sobre el agente agresor y cómo iniciar un tratamiento empírico. Los patrones que muestran heridas por punción se relacionan con dientes largos, afilados y delgados, que se relacionan con los gatos domésticos, las cuales tienden a infectarse con mayor probabilidad debido a la dificultad de su limpieza. ${ }^{2,5}$ Las heridas penetrantes y por aplastamiento se relacionan con dientes cortos, redondos y planos, las cuales se asocian a las mordidas por caninos domésticos. Las heridas por mordida ocasionan lesiones en los tejidos blandos, incluso pueden ocasionar fracturas. Las zonas más afectadas incluyen los labios, mentón, nariz y orejas..$^{5,8}$

Las heridas pueden clasificarse de acuerdo con los tejidos que afectan según la clasificación de Lackmann. $3,5,8$

I. Herida superficial sin involucrar el músculo.

II. Herida profunda que involucra el músculo.

III. Herida profunda que involucra el músculo y causa un defecto del tejido.

IVa. Estadio III con afectación vascular o nerviosa.

IVb. Estadio III con afectación de hueso o defecto de algún órgano.

La flora bacteriana que coloniza este tipo de heridas contaminadas prácticamente es la misma entre las mordidas por animales y humanos a excepción de la presencia de especies de Pasteurella en animales. ${ }^{3}$ Los subtipos de bacterias de esta familia que se han encontrado en heridas por caninos es la Pasteurella canis, mientras que en los felinos se presenta principalmente Pasteurella multocida y séptica. ${ }^{9,10}$ La flora bacteriana aeróbica incluye estreptococo alfa y beta hemolítico, S. aureus, S. epidermidis, Escherichia coli, Pseudomonas y Moraxella. Las bacterias anaeróbicas que comúnmente se presentan son especies de Bacteroides, Prevotella y Fusobacterium. ${ }^{2,3,7,10}$

Los pacientes que sufren heridas por mordida están expuestos al Clostridium tetani, el cual se encuentra normalmente en la tierra y en el tracto intestinal de ciertos animales, lo cual puede ocasionar tétanos. ${ }^{2}$ El manejo mediante vacunas antitetánicas en heridas contaminadas de este tipo es un principio quirúrgico básico, por lo que es de vital importancia obtener un historial de inmunizaciones. 1,3,7,10 $^{2}$ 
La rabia es otra de las enfermedades que puede ser transmitida por cualquier animal, principalmente los salvajes. ${ }^{3,7}$ Este agente patógeno viaja a través de nervios periféricos hasta proliferar en la sustancia gris. Posteriormente se puede propagar a glándulas salivales, glándulas adrenérgicas, los músculos y el corazón. La incubación puede variar de semanas a años. Los síntomas en animales que tienen este padecimiento incluyen ataques sin provocación y un comportamiento extraño. Al presentar este comportamiento el animal agresor se deberá mantener en observación e incluso sacrificar para realizar estudios confirmatorios de ser portador. ${ }^{2,10}$ Los signos de infección en el humano al ser contagiado incluyen disfunción cerebral, ansiedad, confusión, agitación, desarrollo de delirio, insomnio, alucinaciones y comportamiento anormal. Por lo que al mostrar estos síntomas deberá obtenerse un historial completo de inmunizaciones para emitir el tratamiento adecuado.

El manejo inicial de este tipo de trauma deberá seguirse de acuerdo al protocolo de apoyo vital en trauma (ATLS). 2,7,10 Se deberá efectuar un minucioso examen físico general así como el ambiente donde se llevó acabo el incidente y el tiempo transcurrido desde la agresión. Deberán realizarse estudios de imagen para descartar daños a estructuras vasculares así como óseas en caso de sospecha de daño. ${ }^{7}$

El empleo de antibióticos profilácticos es controvertido, la primera elección como antibiótico empírico es la amoxicilina con ácido clavulánico, ${ }^{2-4,10,11}$ seguida de fluoroquinolonas y clindamicina. Algunos autores recomiendan el uso obligatorio de profilaxis antibacteriana en heridas con seis a ocho horas de evolución sin tratamiento. 2,3,10

El manejo quirúrgico se debe enfocar en la limpieza de la herida, la cual se debe llevar a cabo mediante la irrigación a presión mediante agua salina. ${ }^{2,7,10}$ Incluso se ha propuesto el uso de soluciones hiperoxidadas así como de yodo. ${ }^{3}$ Se recomienda el cultivo del área a tratar, esto a consecuencia de la flora mixta que presenta. Se deberán tomar en cuenta aquellas heridas profundas por punción al extender la herida para tener un mejor acceso durante el lavado quirúrgico..$^{7,10}$ Una vez realizada la limpieza de la herida se examinará meticulosamente en búsqueda de zonas de hemorragia, las cuales se ligarán o cauterizarán, se desbridará el tejido necrótico. ${ }^{2}$ Se deberá prestar especial atención a aquellas heridas en el cráneo, sobre todo en infantes, ya que son susceptibles a heridas por punción que ocasionan heridas intracraneales. ${ }^{7,10}$ Las estructuras especializadas tales como el nervio facial, el conducto parotídeo o la vía lagrimal deberán ser reparadas en caso de ser necesario., ${ }^{2,7,10}$ El cierre primario de la herida en la región maxilofacial es el tratamiento de elección, por la alta irrigación que se tiene puede llevarse a cabo, como concuerdan la mayoría de los autores, para que se logren los mejores resultados estéticos y funcionales posibles. ${ }^{2-4,10,12}$ Se realizará el cierre mediante puntos profundos con material reabsorbible, reduciendo éstos al mínimo necesario. El cierre de la piel se llevará a cabo mediante material no reabsorbible monofilamento. El empleo de injerto así como la rotación de colgajos se efectuará en caso de ser necesario.

El cuidado postoperatorio conlleva el empleo de antibioticoterapia por cinco a siete días y cuidados propios de la herida. ${ }^{2,3,10}$ La revisión de la cicatriz y los procedimientos secundarios se llevarán a cabo a los seis meses.

\section{CASOS CLÍNICOS}

\section{Caso 1}

Se presenta el caso de paciente masculino de 20 años de edad, sin antecedentes de relevancia para el padecimiento actual. Se nos interconsulta por parte del servicio de urgencias por traumatismo maxilofacial. Al acudir a revisión, dicho paciente se encontraba bajo los efectos del alcohol, sin deterioro neurológico. A la exploración física presenta herida de aproximadamente $3 \mathrm{~cm}$ de longitud en región supraciliar derecha (Figura 1), múltiples heridas en la región craneal derecha, de las cuales la de mayores dimensiones se ubicaba sobre la región parietal con exposición de aponeurosis epicraneal, con dimensiones de $6 \times 8 \mathrm{~cm}$. Sin aparente compromiso de la estructura ósea (Figura 2). Se solicita tomografía axial computarizada en la que no se observan fracturas sobre estructuras óseas. Al interrogatorio indirecto se comenta que es mordido por perro de raza pitbull, al parecer se encontraba alimentándolo. A decir del dueño, el canino contaba con todas sus vacunas al día. Se inicia con medicación empírica, ya que el accidente se había suscitado 48 horas antes, se aplica un doble esquema a base amoxicilina/ácido clavulánico vía oral así como ciprofloxacino intravenoso. Posteriormente se traslada a quirófano una vez cumplido con el protocolo preoperatorio para realizar la debridación y el lavado mediante solución salina de las heridas, se efectuará el cierre por primera intención mediante sutura no reabsorbible monofilamento, asimismo se fijan drenajes tipo 


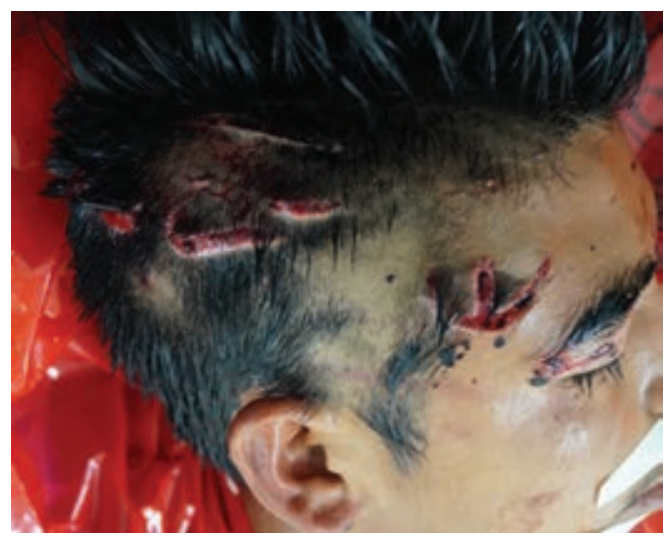

Figura 1: Herida de espesor total en región supraciliar y parietal.

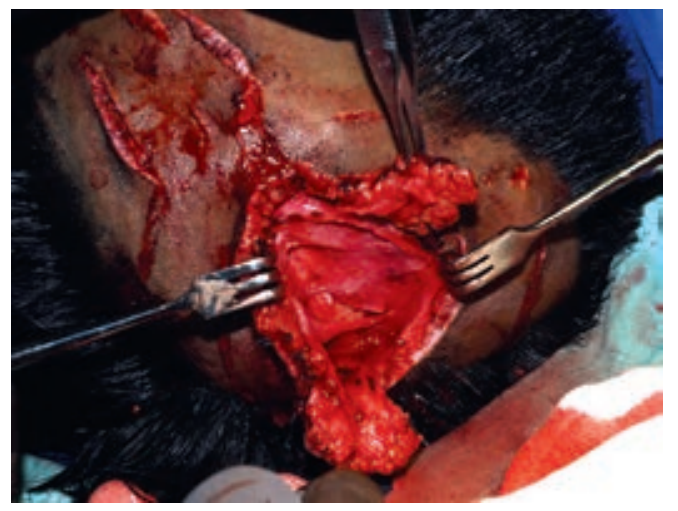

Figura 2: Herida de espesor total en región parietal y occipital.
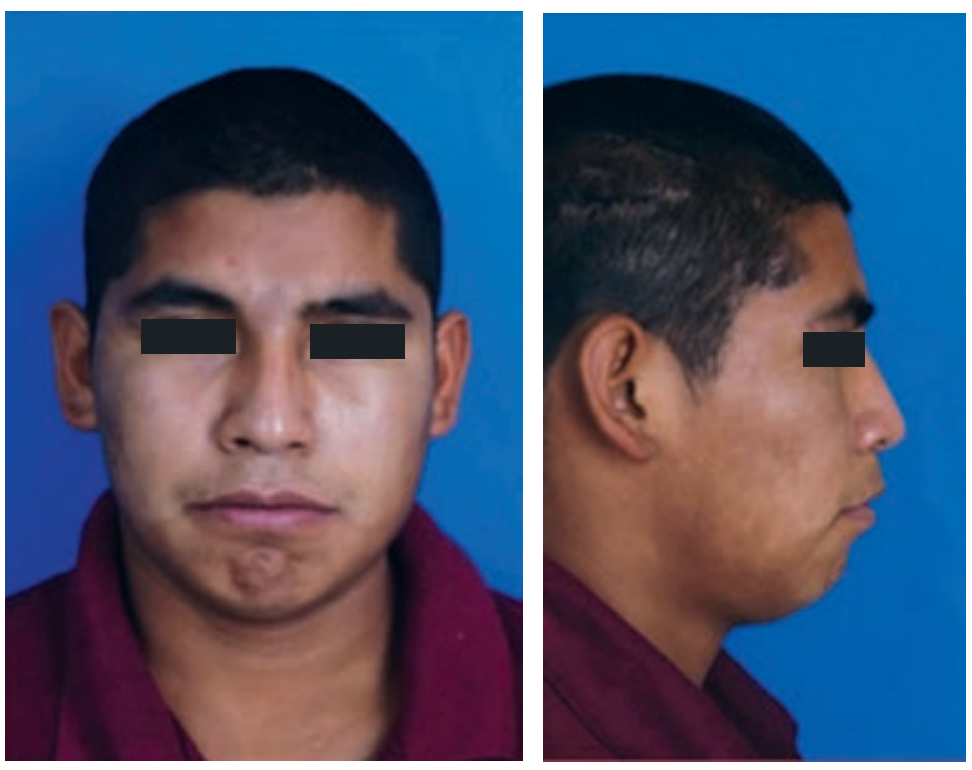

Figura 4: Imagen postoperatoria del paciente.
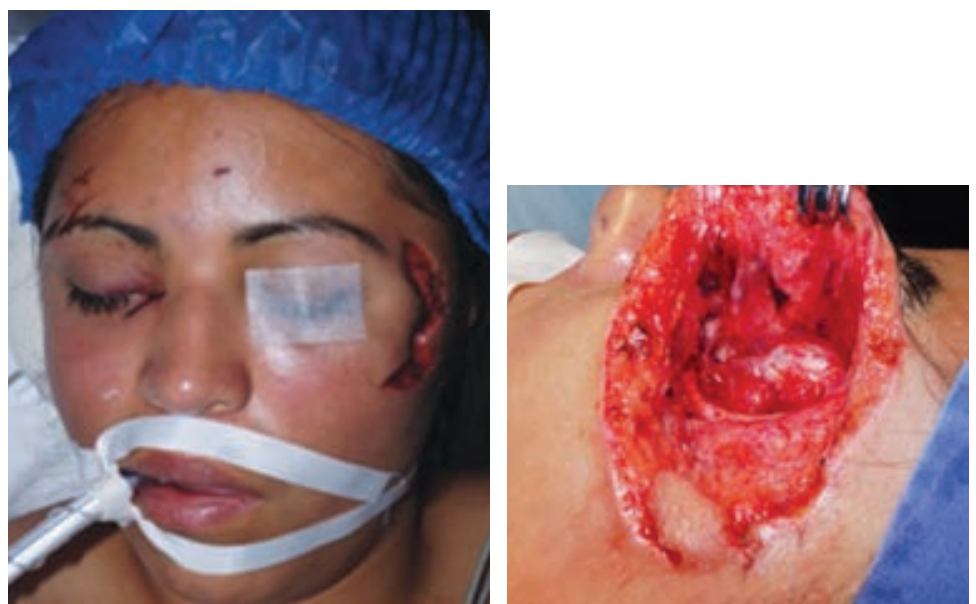

Figura 5: Herida en región facial y órbito-geniana izquierda.
Figura 3:

Cierre por primera intención de heridas más colocación de drenaje.
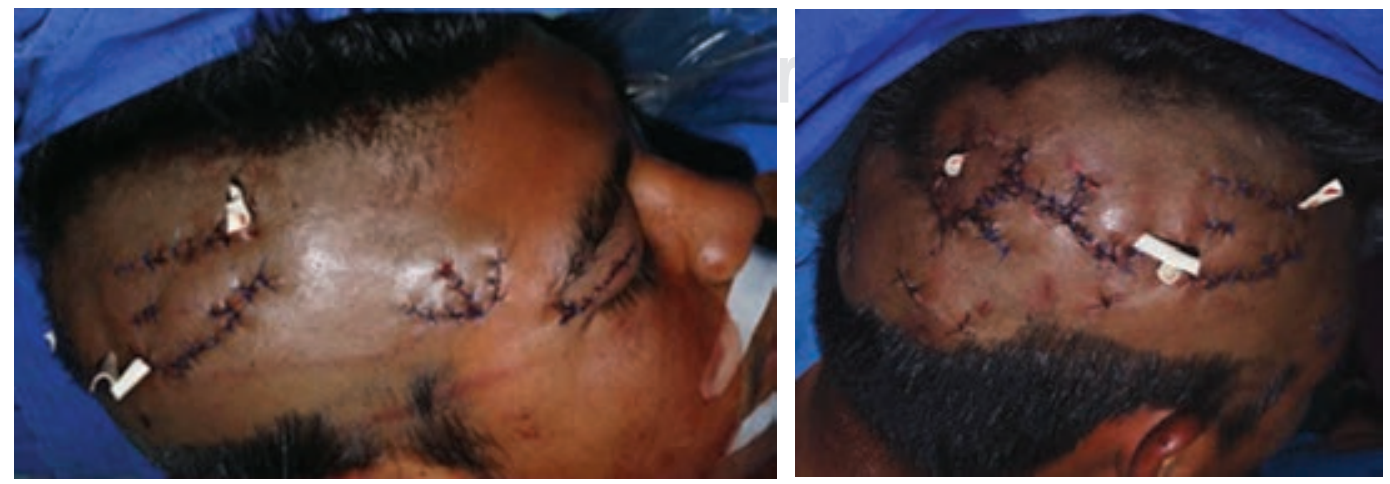
Figura 6:

Herida en región supraciliar, frontal y canto interno izquierdo.
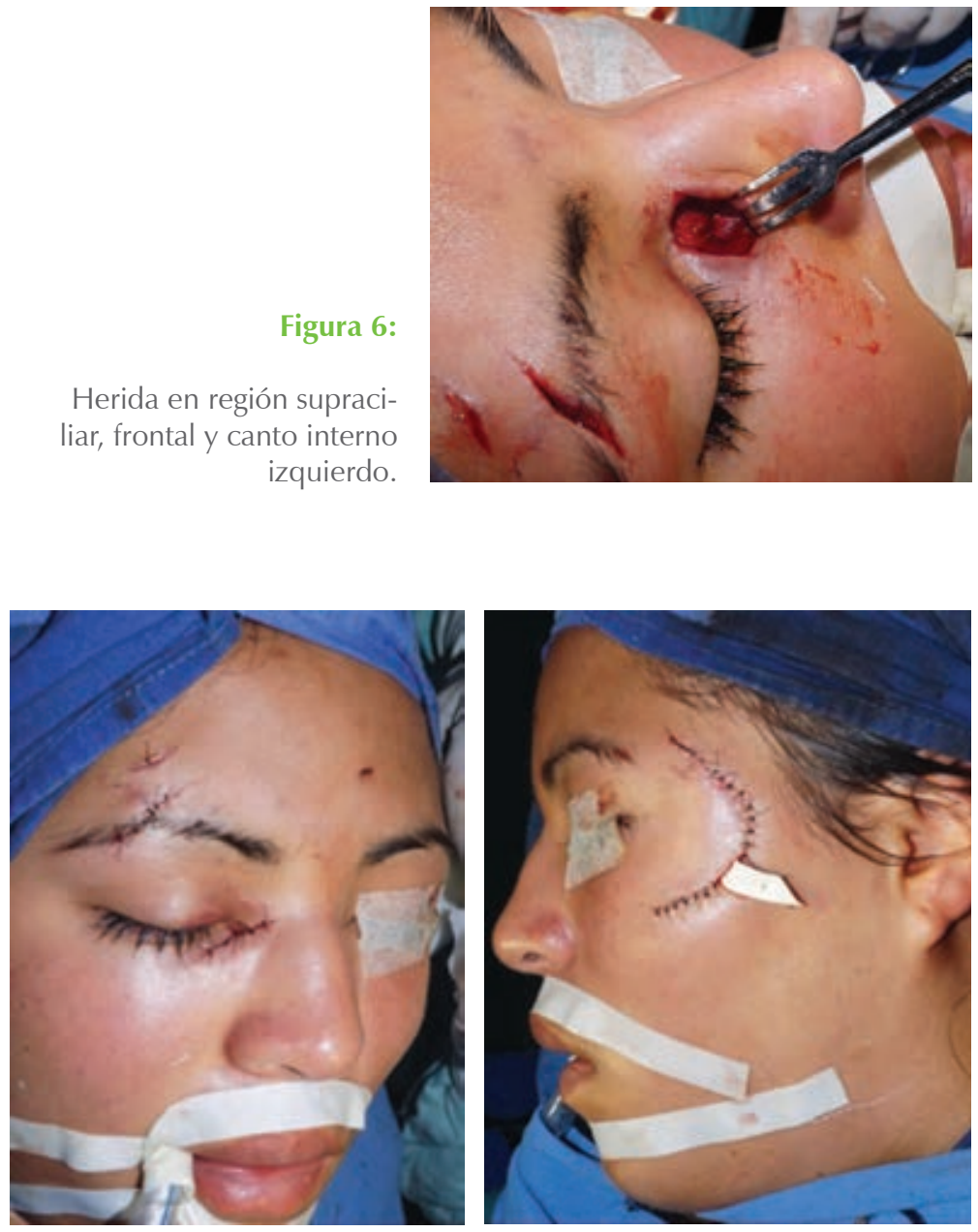

Figura 7: Cierre primario de heridas más colocación de drenaje tipo Penrose.
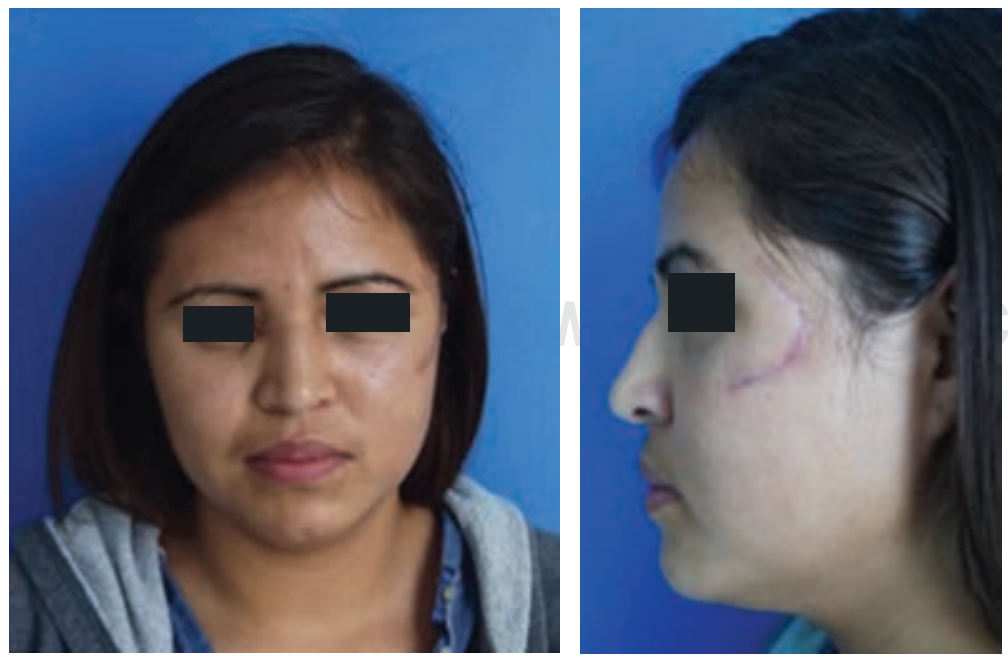

Figura 8: Imagen postoperatoria del paciente.

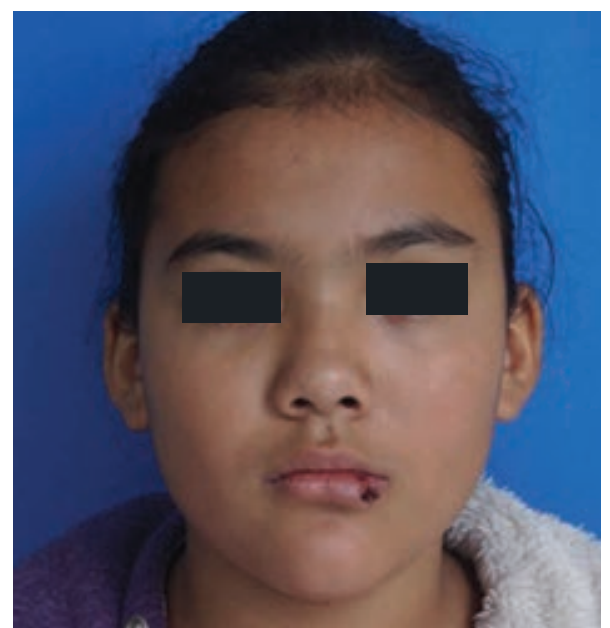

Figura 9: Herida en región labial izquierda.

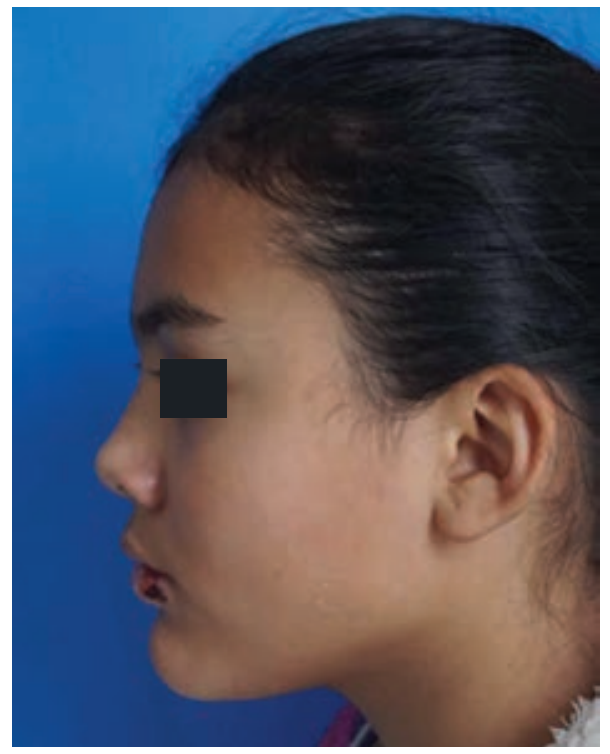

Figura 10: Herida situada en la región mucopiel de labio inferior izquierdo.

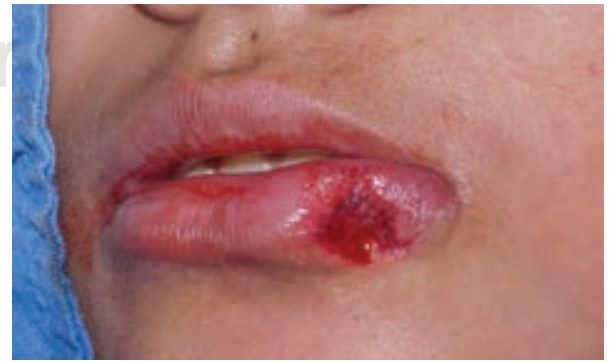

Figura 11: Herida de tipo avulsiva, cicatrización por segunda intención. 
Penrose en las heridas de mayor longitud debido al espacio muerto que generaba (Figura 3). El paciente se mantuvo hospitalizado cinco días manteniendo el esquema antes mencionado. A su egreso se mantiene el esquema farmacológico hasta cumplir 10 días. Los drenajes se retiran al cabo de tres días y el material de sutura a los siete días. El paciente cursó sin complicaciones y fue enviado a medicina preventiva donde no requirió la aplicación de vacunas antirrábica o tetánica (Figura 4).

\section{Caso 2}

Paciente femenino de 16 años de edad, sin antecedentes de relevancia para el padecimiento actual. Se interconsulta al servicio de cirugía maxilofacial por parte de urgencias adultos por traumatismo en región facial. Al interrogatorio la herida tenía antigüedad de 72 horas, por lo que se inicia antibioticoterapia empírica mediante amoxicilina/ácido clavulánico vía oral así como clindamicina intravenosa. La paciente menciona haber sido atacada por canino de raza labrador al encontrarse jugando con él. A la revisión, la paciente estaba tranquila, cooperadora, ubicada en las tres esferas neurológicas de la conciencia que a la exploración física mostraba herida en región geniana izquierda de aproximadamente $8 \mathrm{~cm}$ de longitud (Figura 5), curvilínea de bordes irregulares y necróticos, presentando material de cicatrización sin daño al $\mathrm{V}$ par craneal. Se aprecian tres heridas en región periorbitaria, a nivel de canto interno derecho de aproximadamente $3 \mathrm{~cm}$ de longitud sin daño a vía lagrimal, la segunda herida en región supraciliar derecha de $2 \mathrm{~cm}$ de longitud y la tercera a nivel de la región frontal derecha de $1 \mathrm{~cm}$ de longitud (Figura 6). Se realizan estudios de imagen, los cuales descartan fracturas. Una vez completado el protocolo prequirúrgico se traslada a quirófano donde bajo anestesia general balanceada se exploran heridas, se ligan vasos, se desbrida tejido necrótico y se realiza lavado quirúrgico a base de solución salina. La herida de mayor dimensión situada en región geniana derecha presentaba comunicación a cavidad orbitaria, sin compromiso visual y sin fracturas de la misma. Se procede a la plastia de los bordes de la herida y se realiza cierre de primera intención, fijando drenaje tipo Penrose sobre cierre debido al espacio muerto resultante (Figura 7). La paciente cumple con estancia intrahospitalaria de tres días, al egreso se retira el drenaje y al cabo de días se retira el material de sutura sin complicaciones.
Se interconsulta con medicina preventiva, quienes aplican dosis de toxoide tetánico (Figura 8).

\section{Caso 3}

Femenino de nueve años de edad, sin antecedentes de relevancia para el padecimiento actual. Nuestro servicio es interconsultado por urgencias pediatría por mordida de canino. Al interrogatorio indirecto nos comenta padre que recibió mordida por parte de canino domestico de la raza Chihuahua hace 36 horas, menciona que el canino cuenta con las vacunas adecuadas. La paciente se encuentra tranquila, presenta herida avulsiva de aproximadamente $2 \times 2 \mathrm{~cm}$. En región de labio inferior izquierdo, sin involucrar la comisura labial, sin datos de infección (Figuras 9 a 11), por lo que bajo anestesia local se realiza la debridación y el lavado quirúrgico de la herida. A causa de la pérdida de tejido se decide cicatrizar la herida por segunda intención para evitar la deformidad labial debido a la contracción del tejido.

La paciente transcurrió sin datos de infección, se manejó mediante antibiótico profiláctico amoxicilina/ clavulanato por un periodo de siete días.

\section{DISCUSIÓN}

El manejo inicial de las heridas ocasionadas por mordidas de animales se basa en una adecuada irrigación y debridación de las mismas, esto para favorecer un ambiente limpio libre de contaminación para el cierre primario. La solución salina es el agente de elección, ya que la irrigación se basa en el efecto mecánico y no en la actividad antibacteriana del agente..$^{8,10,13}$ Se ha recomendado el uso de iodopovidona al $1 \%$, pero no se ha observado un efecto superior a la solución salina, por otro lado, puede ocasionar irritación sobre los tejidos, lo que provoca la disminución del aporte sanguíneo. La debridación deberá ser lo más conservadora posible para evitar la pérdida de tejido sano innecesariamente y así ofrecer los mejores resultados estéticos posibles. ${ }^{2,10,13}$

Las infecciones en la región de cabeza y cuello tienen índices bajos, esto principalmente se atribuye a la gran irrigación que existe. Las heridas ocasionadas por felinos se asocian a mayor incidencia de infección debido a las heridas profundas que provocan, las cuales se relacionan con la inoculación de mayor profundidad de agentes patógenos. El retraso en la atención de las heridas después de seis a 12 horas aumenta el riesgo de infección. 
Una de las controversias que existe sobre el manejo de este tipo de trauma es el cierre primario de dichas heridas, debido principalmente a que se cree que aumenta el riesgo de infecciones. Cheng y colaboradores ${ }^{14}$ realizaron un metaanálisis de la literatura existente en el que concluyeron que el cierre primario no aumenta significativamente la posibilidad de infección. Por otro lado, esto ayuda a manipular mejor los tejidos, ya que el edema puede dificultar el cierre secundario y con el cierre primario se pueden lograr mejores resultados estéticos. Nikolaos y colaboradores ${ }^{15}$ en su estudio de heridas mediante cierre primario concluyeron que en el área de la cara y cabeza existen mejores resultados estéticamente mediante el cierre primario, la incidencia de infección es mucho menor que en otras partes del cuerpo. Por lo que el cierre primario se recomienda para el tratamiento de estas heridas como primera elección a excepción de las heridas avulsivas. ${ }^{7,16}$

Hay diversas opiniones sobre el uso de antibióticos de manera profiláctica. Aunque la mayoría concuerda en que el empleo de éstos puede disminuir la incidencia de una infección. ${ }^{2,15,16} \mathrm{Si}$ bien es cierto que sólo 4\% de las heridas por caninos son susceptibles a infectarse, las mordidas por gatos y humanos son una indicación absoluta; la comunidad de la cirugía maxilofacial sugiere principalmente el uso de una antibioticoterapia profiláctica en mordidas por caninos a base de amoxicilina/ clavulanato como primera elección. ${ }^{2,10,16}$

\section{CONCLUSIÓN}

El manejo de las heridas por mordidas puede ser complejo debido a las diferentes presentaciones que pueden citarse. El compromiso estético puede ser devastador para el afectado.

Las infecciones son las complicaciones más comunes de esta entidad, aunque las situadas en el área maxilofacial son de bajo riesgo. El manejo inicial mediante una irrigación y debridación adecuada disminuye el riesgo. El cierre primario se deberá realizar dentro de lo posible con el fin de lograr resultados estéticos aceptables, ya que las secuelas psicológicas pueden ser devastadoras. Se deberá tomar en cuenta el historial de vacunación para emitir una interconsulta en los casos de no contar con las inmunizaciones antitetánicas correspondientes así como de la rabia. Las mordidas pueden transmitir infecciones virales como la hepatitis $\mathrm{B}$ y $\mathrm{C}$ así como el VIH y sífilis, por lo que se sugiere un interrogatorio escrupuloso y un tratamiento multidisciplinario.

\section{BIBLIOGRAFÍA}

1. Harrison M. A 4-year review of human bite injuries presenting to emergency medicine and proposed evidence-based guidelines. Injury. 2009; 40 (8): 826-830.

2. Stefanopoulos PK, Tarantzopoulou AD. Facial bite wounds: management update. Int J Oral Maxillofac Surg. 2005; 34 (5): 464472.

3. Kesting MR, Hölzle F, Pox C, Thurmüller P, Wolff KD. Animal bite injuries to the head: 132 cases. Br J Oral Maxillofac Surg. 2006; 44 (3): 235-239.

4. Monroy A, Behar P, Nagy M, Poje C, Pizzuto M, Brodsky L. Head and neck dog bites in children. Otolaryngol Head Neck Surg. 2009; 140 (3): 354-357.

5. Jaindl M, Grünauer J, Platzer P, Endler G, Thallinger C, Leitgeb J et al. The management of bite wounds in children--a retrospective analysis at a level I trauma centre. Injury. 2012; 43 (12): 2117-2121.

6. Abu-Zidan FM, Eid HO, Hefny AF, Bashir MO, Branicki F. Camel bite injuries in United Arab Emirates: a 6 year prospective study. Injury. 2012; 43 (9): 1617-1620.

7. Morgan JP 3rd, Haug RH, Murphy MT. Management of facial dog bite injuries. J Oral Maxillofac Surg. 1995; 53 (4): 435-441.

8. Wolff KD. Management of animal bite injuries of the face: experience with 94 patients. J Oral Maxillofac Surg. 1998; 56 (7): 838-843; discussion 843-844.

9. Talan DA, Citron DM, Abrahamian FM, Moran GJ, Goldstein EJ. Bacteriologic analysis of infected dog and cat bites. Emergency Medicine Animal Bite Infection Study Group. N Engl J Med. 1999; 340 (2): 85-92.

10. Stefanopoulos PK. Management of facial bite wounds. Oral Maxillofac Surg Clin North Am. 2009; 21 (2): 247-257, vii.

11. Gilbert DN, Moellering Jr RC, Eliopoulos GM, Sande MA. The sanford guide to antimicrobial therapy. 34th ed. Hyde Park: Antimicrobial Therapy Inc.; 2004. p. 35.

12. Lieblich SE, Topazian RG. Infection in the patient with maxillofacial trauma. In: Fonseca RJ, Walker RV eds. Oral and maxillofacial trauma. 2nd ed. WB Saunders: Philadelphia; 1997. pp. 1248-1273.

13. Javaid M, Feldberg L, Gipson M. Primary repair of dog bites to the face: 40 cases. J R Soc Med. 1998; 91 (8): 414-416.

14. Cheng HT, Hsu YC, Wu Cl. Does primary closure for dog bite wounds increase the incidence of wound infection? A metaanalysis of randomized controlled trials. J Plast Reconstr Aesthet Surg. 2014; 67 (10): 1448-1450.

15. Paschos NK, Makris EA, Gantsos A, Georgoulis AD. Primary closure versus non-closure of dog bite wounds. a randomised controlled trial. Injury. 2014; 45 (1): 237-240.

16. Baurmash HD, Monto M. Delayed healing human bite wounds of the orofacial area managed with immediate primary closure: treatment rationale. J Oral Maxillofac Surg. 2005; 63 (9): 13911397.

Conflicto de intereses: No hay conflicto de intereses. 